\title{
HISTÓRIA DA ORTOGRAFIA KARAJÁ: LUTA PELA SOBREVIVÊNCIA DA LIINGUA KARAJÁ
}

\author{
LARIWANA ${ }^{1}$, Leandro Karajá \\ Pesquisador da Ação 'Saberes Indígenas na Escola'
}

\section{RYBÈNA BUTÈ}

Kaa aõmysỹdỹỹna-ò rèòryrènyra timybo iny rybè rartidỹỹmyhỹre bdèdỹỹnana. Tuu rybè hèka aõni awi rare raerytyhykremy irtidỹỹ irumy iny rybè rarekèmy, kièmy dori irtidỹỹki tiièmy roimy rarekre irèrbi tuu lobxi rỹikremy, tai dori irè rybè raruti rỹityhykre irbi tahè tyyrtidu, tiirtidỹỹdu mahãdu rièrymy rỹirakremy timybo rybè rèlèmyhỹre bdèdỹỹnana, iwsèmy riwinymy rỹirakre inatxi-my rybèna.

Rybèna wèryna: Inyrybè. Rybèrtidỹỹ. Rybèirumyrỹikè.

\section{RESUMO}

Buscamos, neste trabalho, apresentar alguns aspectos ortográficos da língua Karajá/Inyrybè. A discussão sobre a ortografia da língua é fundamental para a manutenção da vitalidade linguística da língua Karajá, uma vez que a ortografia funciona para documentação, o que contribui para o fortalecimento da língua e, também, funciona como facilitadora no processo de ensino e aprendizagem da língua nas escolas indígenas interculturais bilíngues.

Palavras-chave: Língua Karajá. Ortografia. Vitalidade linguística.

\section{ABSTRACT}

We present in this work some spelling aspects of the Karajá/Inyrybè language. The discussion about the spelling/ortography of the language is fundamental for the maintenance of the linguistic vitality of the Karaja language, since the spelling works for documentation, which contributes to the strengthening of the language and also works as a facilitator in the teaching and learning process of the language, in the bilingual indigenous intercultural schools.

Key words: Karajá language. Ortography. Linguistics vitality.

1 Rede UFG/UFT/UFMA. Professor de Educação Básica. 
A história da ortografia da língua Karajá teve início com o pesquisador e linguista Dr. David Fortune. Ele foi o criador da escrita em língua Inyrybè e a quem devemos nossa maior gratidão, por ter nos mostrado o caminho. Hoje, nós, os professores Iny, nos baseamos na ortografia tradicional para aperfeiçoar e melhorar a escrita da língua Inyrybè, que, por algum motivo, não foi feita pelo inventor da ortografia.

Hoje nós, os professores, com a orientação da professora Maria do Socorro Pimentel da Silva, estamos convencionando a escrita em Inyrybè, a fim de que fique o mais próximo possível da fala. Porém, estamos cientes de que a correção nunca é gratificada. Sempre terá algum questionamento daqueles que a visitam.

A língua Karajá pertence ao tronco linguístico Macro-Jê. Como grande parte das línguas indígenas brasileiras, a língua Karajá era ágrafa até a década de 1970. De lá pra cá, a escola do povo Iny foi incorporando a educação escolar bilíngue de transição. Neste tipo de educação, a língua funciona como instrumento facilitador da língua portuguesa, o que significa integrar os indígenas à sociedade do povo do ocidente, por meio da educação escolar.

Com a língua escrita, tínhamos a facilidade de aprender, o mais rápido possível, a falar e escrever em português e, posteriormente, integrar os indígenas à sociedade envolvente, o que significa dar adeus à cultura, à língua Karajá, à crença e à arte e, até mesmo, a características fisiológicas, entre outros.

Hoje em dia, com a criação da nova constituição brasileira de 1988, temos o direito de valorizar e de estudar a nossa própria língua na escola, das séries iniciais até o ensino médio, e na licenciatura em Educação Intercultural, curso superior que é oferecido pela Universidade Federal de Goiás (UFG), e foi criado no ano de 2007.

$\mathrm{O}$ movimento da nova ortografia começou com os próprios alunos das escolas Karajá. Eles próprios viam alguns erros na escrita que podiam ser corrigidos e, a partir disso, os professores buscaram a melhoria da escrita em Inyrybè. Durante o primeiro seminário de ortografia, realizado na cidade de São Félix do Araguaia, no estado do Mato Grosso, no período de 02 a 06/03/2006, promovido pela Faculdade de Letras-UFG, em parceria com a extinta FUNAI/ Araguaia, ministrado pela professora Maria do Socorro Pimentel da Silva e o professor Woubedu Karajá, foi criada a escrita de algumas palavras com duas consoantes juntas. Linguisticamente, é quando ocorre o xuá [ə], que na fala do Javaé não existe. 
Os Karajá falam muito mais rápido do que os Javaé, como mostram os exemplos a seguir:

\begin{tabular}{|c|c|c|}
\hline Javaé & Karajá & Tradução \\
\hline Waraura & Wraura & Garça \\
\hline Bèdèradè & Bdèradè & Folha/galho \\
\hline Jumytata & Jumytta & Formiga \\
\hline
\end{tabular}

Comparação de palavras faladas por indígenas Karajá e por Javaé

Depois teve outro seminário para definir o que ficou pendente no primeiro seminário. A discussão ganhou vida e força no decorrer do curso de licenciatura em Educação Intercultural, na UFG, de 2007 a 2011, e até os dias de hoje. O outro seminário foi realizado em 2015, no mês de novembro, na aldeia JK-Ilha do Bananal (TO) e, posteriormente, na aldeia Hãwalòra-MT, em 2016, no mês de setembro, com a participação de todos os professores das duas aldeias - Itxala e Hãwalòra - e dois professores da aldeia Fontoura, um representante da aldeia $\mathrm{JK}$ e um de Macaúba. O seminário foi coordenado pela professora Maria do Socorro Pimentel da Silva, e pelos professores Leandro Lariwana Karajá e Bijawari Karajá. Neste mesmo mês ocorreu uma reunião de um dia na aldeia de Macaúba. Desta participaram os professores de Macaúba e Ibutuna, ambas localizadas na Ilha do Bananal, uma vizinha da outra.

O objetivo do seminário e da reunião foi o fortalecimento da escrita Inyrybè, bem como a valorização da própria língua que, constantemente, corre o risco de ser extinta por influência da língua portuguesa.

Os dois eventos cuidaram bem do uso das vogais e dos seus acentos, como marcam os sons da fala. Os acentos nessas vogais marcam diferenças de significado. No quadro abaixo, podemos conferir alguns exemplos que podem distinguir essas diferenças:

\begin{tabular}{|l|l|l|l|}
\hline Bero & Rio & bèrò & Puba de mandioca \\
\hline Dee & Asa & Dèè & Carne \\
\hline huỹ & Abelha & hùỹ & Seio \\
\hline tỹrè & Cor (azul/verde/amarelo) & ityrè & Em cima \\
\hline
\end{tabular}


A seguir apresentamos as vogais e as consoantes da ortografia da língua Karajá:

Vogais: a ã à è e i ò o õ u ù y ỹ

Consoantes: b d j k $1 \mathrm{~m} \mathrm{n} \mathrm{r} \mathrm{s} \mathrm{t} \mathrm{tx} \mathrm{w} \mathrm{X}$

Na língua Karajá, existem vários sons vocálicos. A maioria deles é representada por uma letra, mas existem casos de dois sons serem representados por uma mesma letra, como nos sons vocálicos [i] e [ł], nas palavras [biÈrE] 'byrè' (esteira) e [błÈrE] 'byrè (pessoa que come muito). $\mathrm{O}$ entendimento do significado fica por conta do contexto. O mesmo processo acontece com [i] e [I], como mostram os exemplos [werr'ri] 'wèriri' (cesta) e [wari'ri] 'wariri' (garça).

Os sons vocálicos nasais [ĩ] e [ẽ] não foram considerados na escrita devido à baixa ocorrência na língua Karajá. Acontece, por exemplo, nas palavras: ãhi, hõi, mokõi, weã, que na fala realizam-se assim: [ã'hĩ], [ho'ĩ], [moko'î], [wẽ'a].

Neste último seminário, foi necessário convencionar o uso do acento nasal na letra 'a', no início da palavra. $\mathrm{Na}$ ortografia tradicional não era necessário colocar o til. Os exemplos a seguir mostram os dois tipos de escrita:

\begin{tabular}{|l|l|l|}
\hline Escrita tradicional & Escrita nova & Tradução \\
\hline Ahãdu & Ãhãdu & Lua \\
\hline Adàhà & Ãdàhà & Cará \\
\hline Ahula & Âhula & Lobo guará \\
\hline Ahu & Âhu & Lago \\
\hline Ahi & Âhi & Muriçoca \\
\hline
\end{tabular}

A descoberta mais importante é que, quando se fala com a vogal 'a' nasal, no início da palavra, ambos os sexos falam a mesma palavra, ou seja, do mesmo jeito, não muda, como acontece na maioria das palavras da língua Karajá. Mas, quando se fala com a vogal 'a' aberta, aí se vê a diferença entre a fala masculina e a feminina, exceto a palavra asara.

Essa palavra não muda, assim como as palavras axua, na fala feminina, e axuka, na fala masculina (açúcar). Essas duas palavras não mudam, no início da palavra, tanto para a fala masculina como para a feminina. Na maioria dos casos, como em arakre (vou 
embora), na fala masculina, e krakre, na fala feminina (vou embora). Nossa língua tem muitas belezas e particularidades que valem a pena ser consideradas nas riquezas da diversidade linguística.

Além do alfabeto, discutimos o uso do hífen (-) e as palavras monossilábicas também foram cuidadosamente estudadas. Para alguns, eles se parecem, se não pesquisar profundamente. $\mathrm{Na}$ língua Inyrybè, somente as posposições, como o $\tilde{o}$, na fala masculina e na fala feminina, são separados por hífen.

Ou seja, o hífen é usado para separar elementos átonos, como as posposições, das palavras com que ocorrem. O hífen é importante para ajudar distinguir os elementos átonos mencionados dos elementos presos tônicos, como em (a)inieru-di 'com dinheiro dele' [nie'rudi] e (b)inierudi 'o que tem dinheiro' [inieru'di]. O uso mais comum do hífen é com posposições que ocorrem com verbos e nomes, como mostram os exemplos 1, 2, 3 e 4 .

1) Weryryỹnyra-kiratxirèri

Menino praia na está

O menino está na praia

2) Nadibèra-òrara

Mãe rio ao foi

Minha mãe foi ao rio

3) Rexihumyhyre-u 'quando termina'

Termina (verbo) quando (posposição)

4) Utura-õ arirokre (m) - ktura-nokarirokre (f) 2 .

Peixe algum comerei (vou comer) peixe algum comerei

Vou comer algum peixe

As palavras monossilábicas são substantivos que precisam de um possuidor para existir, por exemplo, não existe 'si' (ovo) sozinho, despossuído, mas 'sii' (ovo dela/dele). Veja o exemplo: Hãnièsiaritokre 'vou comer o ovo de galinha'. Sabemos que 'si' é uma palavra, porque podemos colocar um modificador entre Hãniè e si, como no exemplo: Hanièura si (ovo de galinha branca). Por isso, é muito importante

$2 \quad \mathrm{O}$ ' $\mathrm{m}$ ' refere-se à fala masculina e o f, à fala feminina. Uma diferença que existe em nossa língua. E é importante para nossa língua. 
estar sempre estudando a escrita Inyrybè, porque existem várias regras que mesmo nós, que estamos sempre estudando, temos nossas dificuldades. Agora, nosso desafio é estudar partes gramaticais, para facilitar a aprendizagem da nossa língua e enriquecê-la ainda mais, pois é muito grande a invasão linguística pela língua portuguesa e os empréstimos vindos diretos da língua invasora.

\section{REFERENCIAS BIBLIOGRÁFICAS}

LARIWANA KARAJÁ, Leandro. Relatório das atividades de pesquisa realizadas - Projeto "Empréstimos lingüísticos na Língua Karajá" (Observatório da Educação Escolar Indígena - CAPES). Goiânia: UFG/Núcleo Takinahaky) de Formação Superior de Professores Indígenas, 2011.

PIMENTEL DA SILVA, M.do.S.. Relatório do Seminário de Iny Rybè Projeto „Saberes Indígenas na Escola do povo Karajá- SECADI/MEC). Goiânia: UFG/Núcleo Takinahaky) de Formação Superior Indígena, 2016.

PIMENTEL DA SILVA, M.do.S. A função Social do Mito na Revitalização da Língua e da Cultura Karajá. Tese de Doutorado. PUC, São Paulo, 2001. RIBEIRO, Eduardo Rivail. Empréstimo Tupí-Guarani em Karajá. In: Revista do Museu Antropológico, v.5/6, n.1, p.75-97. Editora da UFG, 2001. 